\title{
Knowledge and Perception of Genetically Modified Foods among Agricultural workers in Jos Metropolis, Plateau State
}

Daboer $\mathrm{JC}^{1}$, Bulus $\mathrm{NG}^{2}$, Ayiga $\mathrm{EG}^{2}$, Yako $\mathrm{JB}^{2}$, Zoakah $\mathrm{AI}^{1}$.

${ }^{1}$ Department of Community Medicine, University of Jos

${ }^{2}$ Department of Community Medicine Jos University Teaching Hospital.

Correspondence: Dr JC Daboer:e-mail: jonathandabor@yahoo.co.uk, phone+2347038959300

\begin{abstract}
Background: Genetically modified foods are agricultural products with specific changes introduced into their DNA by genetic engineering techniques so as to favour the production of a desired biological product. Knowledge of genetically modified foods among agricultural workers remains largely unknown in our environment. The objective of this study was to assess the knowledge and perception of these products among agricultural workers in Jos.
\end{abstract}

Methods: This was a cross sectional study using a structured selfadministered questionnaire. Respondents were selected through stratified sampling technique. Data collected were analysed using Statistical Package for Social Sciences version 23 software. Knowledge and perception of genetically modified foods were scored. Factors influencing the observed knowledge and perception were also assessed and a p value of $\leq 0.05$ was considered statistically significant.

Results: The mean age of respondents was $41.9 \pm 8.6$ years with $66.1 \%$ of them being males. One hundred and sixty five (94.8\%) had tertiary education and the median years of work experience was 12 years (interquartile range 6.0-20.3). There was good knowledge and perception of genetically modified foods in $48.3 \%$ and $29.9 \%$ of the respondents respectively. Statistically significant associations were found between the length of work experience and both knowledge $(p=0.039)$ and perception ( $p=0.011)$ of genetically modified foods.

Conclusion: Both the knowledge and perception of genetically modified foods were low. Duration of work significantly influenced both knowledge and perception of genetically modified foods. It is recommended that agricultural institutions improve the knowledge of their workers on genetically modified foods by regular and continuous training.

Keywords: Genetic foods, agriculture, knowledge, perception

\section{Introduction}

Genetically Modified Organisms (GMOs) are those with genetic materials altered by man through transferring a gene from one species to another.' These GMOs have specific changes introduced into their DNA by genetic engineering techniques and this is to favor the expression of desired physiological traits or the production of a desired biological product. ${ }^{2}$ Application of genetic engineering has 
appeared in a number of areas, ranging from agriculture to chemical engineering, the food industry, medicine, molecular biology, environmental protection and human health. ${ }^{3}$ Genetically Modified Foods (GMFs) in agriculture are some of the most frequently cited examples of GMOs. Benefits of GMFs in agriculture include increased yields, reduced costs of food or drug production, reduced need for pesticides, enhanced nutrient composition and food quality, resistance to pests and disease, greater food security and medical benefits to the world's growing population. Advances have also been made in developing crops and livestock that mature faster and tolerate environmental stressors better, allowing them to grow in conditions where they might not otherwise flourish. ${ }^{4}$

Genetically modified foods have been in the market for some time now and make up a significant proportion of the food consumed by many persons the world over. ${ }^{4}$ The level of knowledge of GMFs and the understanding of the technology behind GMFs remain largely unknown

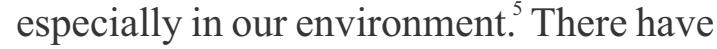
been growing interests and concerns about ethical and social issues concerning GMFs not only in the scientific community but also among the general public. ${ }^{3}$ One of the sectors with the greatest potential to benefit from GMF technology is agriculture. This explains why agriculturists globally have been in the forefront of the promotion of this technology in recent years. A sound knowledge of GMFs among agricultural workers will be imperative not only for the appropriate application of this technology in agriculture but also for communicating its benefits to consumers of GMFs.

Surveys conducted in the United States of America reported that consumers were poorly knowledgeable about GMFs with only $43 \%$ to $48 \%$ knowing that GMFs were available in supermarkets and $26 \%$ to $31 \%$ believing that they had probably eaten GMFs. Between $48 \%$ to $54 \%$ selfrated themselves as knowing little or nothing at all about GMFs. ${ }^{6}$ There was, however, high awareness of GMFs among farmers in Brazil and India with studies reporting $82 \%$ awareness in India. ${ }^{1,7}$ In Ghana, $54.8 \%$ of the farmers were aware of GMFs. ${ }^{8}$ Studies assessing the knowledge and perception of GMFs among agricultural workers in Nigeria are limited. The aim of this study, therefore, was to assess the knowledge and perception of GMFs among workers in organized agricultural institutions in Jos, Plateau State. Information from this study would provide baseline data on the knowledge of GMFs and their perception among this group of workers in Nigeria. It was also expected to inform the development of a research agenda and further education in this field in the country.

\section{Methods}

The study was carried out in the Jos Metropolis which is made up of Jos North and Jos South Local Government Areas (LGAs). These two LGAs together make up the capital of Plateau State. Plateau State is one of the thirty-six states in Nigeria, located in the central part of the Country. It is bounded by Bauchi State to the Northeast, Kaduna State to the Northwest, Nasarawa State to the Southwest and Taraba State to the Southeast. Plateau State is host to a number of agricultural organizations, many of which are situated in Jos Metropolis. These organizations carry out commercial farming, research, extension services and training of agricultural workers. The trained agricultural workers in these organizations constituted the study population.

The study used a cross sectional study 
design. The sample size was determined to be 171 based on an acceptable error margin (d) of 0.05 and a proportion with good knowledge of GMFs (P) of 87.3\% obtained from a previous study. We used the Cochrane's formula for determining sample size in descriptive studies: $\mathrm{n}=$ $\mathrm{Z}^{2} \mathrm{PQ} / \mathrm{d}^{2}$ where $\mathrm{n}$ is the minimum sample size. ${ }^{10}$ After adding $10 \%$ of the calculated value to allow for non-response, the sample size came to 188 .

Out of the 7 agricultural organizations in the Jos metropolis, 5 were selected by simple random sampling technique using balloting. The calculated sample size was then proportionately allocated to the selected organizations according to the sizes of their trained workforce. In each of the selected organizations, systematic sampling technique was used to select the respondents. The list of trained staff in each organization served as the sampling frame. A sampling interval was calculated using the total number of trained staff on the list as numerator and the number of respondents allocated to that organization as denominator. Using these sampling intervals, the number to be selected from all 5 organizations was obtained to achieve the minimum sample size. All trained agriculturists employed in the organizations were included leaving out administrative, accounting and engineering staff. Trained staff that could not be reached despite repeated visits were excluded from the study.

A structured self-administered questionnaire, developed by the researchers for this study, which had earlier been pre-test at the Plateau State College of Agriculture Garkawa, was then used for data collection. Data collected in this questionnaire covered sociodemographic characteristics as well as knowledge and perception of GMFs among the agricultural workers.
Knowledge questions were scored and a respondent who got at least $50 \%$ of the questions correct was adjudged to have good knowledge while any one that got less than $50 \%$ of the questions correct was considered to have poor knowledge of GMFs. Similarly any respondent that gave the correct answers to at least $50 \%$ of the questions on perception was considered to have good perception while any one that got less than $50 \%$ of the questions correct was considered to have poor perception of GMFs. The proportions of agricultural workers with good knowledge and those with good perception of GMFs were then determined. Data was analyzed using the Statistical Package for Social Sciences (SPSS) version 23. Associations between the socio-demographic characteristics of the workers and their knowledge and perception of GMFs were tested using Chi square test and a $\mathrm{p}$ value $\leq 0.05$ was considered statistically significant.

Permission for the study was obtained from the managements of the organizations selected for the study. Written informed consent was obtained from each respondent and confidentiality of all information collected was assured and ensured as no personal identifiers were taken from them. Detailed explanations were made to the respondents to ensure they understood the nature and risks involved in participating in the study before they signed the consent forms.

\section{Results}

A total of 174 out of the 190 questionnaires distributed were properly filled and returned, giving a response rate of $91.6 \%$. Majority (over $61 \%$ ) of the respondents were 40 years and above with mean of age distribution of $41.9 \pm 8.6$ years while $94.8 \%$ had tertiary education. Table 1

The proportion of respondents with good 
knowledge was $48.3 \%$ and good perception $29.9 \%$ with undergraduate curriculum serving as the highest (35.6\%) and traditional media serving as the lowest (7.5\%) sources of information on GMFs. Table 2 .There was a statistically significant association between years of work experience and knowledge of GMFs $(\mathrm{p}=0.039)$. Table 3

Table 4 shows there was a statistically significant association between years of work experience and perception of GMFs $(p=0.011$

Table 1: Socio-demographic profiles of respondents

\begin{tabular}{lrc}
\hline Parameter & Frequency & Percentage \\
\hline Age(years) & 12 & \\
$20-29$ & 55 & 6.9 \\
$30-39$ & 64 & 31.6 \\
$40-49$ & 43 & 24.7 \\
$50+$ & & \\
Sex & 115 & 66.1 \\
Males & 59 & 33.9 \\
Females & & \\
Marital Status & 28 & 16.1 \\
Single & 146 & 83.9 \\
Married & & \\
Educational Status & 9 & 5.2 \\
No Tertiary Education & 165 & 94.8 \\
Tertiary & & \\
Years at Work & 61 & 35.1 \\
$0-9$ & 59 & 33.9 \\
10-19 & 38 & 21.8 \\
$20-29$ & 16 & 9.2 \\
$30+$ & $\mathbf{1 7 4}$ & $\mathbf{1 0 0}$ \\
Total & &
\end{tabular}

Mean age $=41.9 \pm 8.6$ years, median years of work experience $=12$ years

$(\mathrm{IQR}=6.0-20.3$ years $)$

Table 2: Categories of Knowledge and Perception of GMFs

\begin{tabular}{lcc}
\hline Parameter & Frequency & Percentage \\
\hline Knowledge of GMFs & 84 & 48.3 \\
Good & 90 & 51.7 \\
Poor & 52 & 29.9 \\
Perception of GMFs & 122 & 70.1 \\
Good & & \\
Poor & 13 & 7.5 \\
Source of Information* & 40 & 23.0 \\
Traditional Media & 62 & 35.6 \\
Social Media & 27 & 15.5 \\
Undergraduate Curriculum & & \\
Seminars/Workshops &
\end{tabular}

*32 respondents did not mention any source of information 
Table 3: Association between socio-demographic characteristics and knowledge of GMFs

\begin{tabular}{lrrrrrr}
\hline Parameter & $\begin{array}{l}\text { Knowledge } \\
\text { Good (\%) }\end{array}$ & $\begin{array}{l}\text { Knowledge } \\
\text { Poor (\%) }\end{array}$ & Total & df & $\mathbf{X}^{2}$ & p-value \\
\hline Age & $7(58.3)$ & $5(41.7)$ & 12 & 3 & 4.414 & 0.220 \\
$20-29$ & $21(38.2)$ & $34(61.8)$ & 55 & & & \\
$30-39$ & $36(56.3)$ & $28(43.7)$ & 64 & & & \\
$40-49$ & $20(46.5)$ & $23(53.5)$ & 43 & & & \\
$50+$ & $60(52.2)$ & $55(47.8)$ & 115 & 1 & 2.064 & 0.151 \\
Sex & $24(40.7)$ & $35(59.3)$ & 59 & & & \\
Males & & & & & & \\
Females & $13(46.4)$ & $15(53.6)$ & 28 & 1 & 0.046 & 0.831 \\
Marital Status & $71(48.6)$ & $75(51.4)$ & 146 & & & \\
Single & & & & & & \\
Married & $2(22.2)$ & $7(77.8)$ & 9 & 1 & $2.741 *$ & 0.098 \\
Educational & & & & & & \\
Status & $82(49.7 \%)$ & $83(50.3)$ & 165 & & & \\
No Tertiary & & & & & & \\
Education & & & & & \\
Tertiary & $25(41.0)$ & $36(59.0)$ & 61 & 3 & 8.368 & 0.039 \\
Years of Work & $27(45.8)$ & $32(54.2)$ & 59 & & & \\
Experience & $6(68.4)$ & $12(31.6)$ & 38 & & & \\
$0-9$ & $10(62.5)$ & 16 & & & & \\
$10-19$ & & & & & \\
$20-29$ & & & & & & \\
$30+$ & & & & & & \\
\hline
\end{tabular}

*Adjusted Chi square 
Table 4: Association between socio demographic characteristics and perception of GMFs

\begin{tabular}{lrrrrrr}
\hline Parameter & $\begin{array}{l}\text { Perception } \\
\text { Good (\%) }\end{array}$ & $\begin{array}{l}\text { Perception } \\
\text { Poor (\%) }\end{array}$ & Total & df & $\mathbf{X}^{\mathbf{2}}$ & p-value \\
\hline Age (years) & $4(33.3)$ & $8(66.7)$ & 12 & 3 & $7.714^{*}$ & 0.052 \\
$20-29$ & $19(34.6)$ & $36(65.4)$ & 55 & & & \\
$30-39$ & $23(35.9)$ & $41(64.1)$ & 64 & & & \\
$40-49$ & $6(14.0)$ & $37(86.0)$ & 43 & & & \\
$50+$ & & & & & 0.686 & 0.407 \\
Sex & $32(27.8)$ & $83(72.2)$ & 115 & 1 & & \\
Males & $20(33.9)$ & $39(76.1)$ & 59 & & & \\
Females & & & & & & 0.081 \\
Marital Status & $9(32.1)$ & $19(67.9)$ & 28 & 1 & 0.776 \\
Single & $43(29.5)$ & $103(70.5)$ & 146 & & & \\
Married & & & & & & \\
Educational Status & $3(33.3)$ & $6(66.7)$ & 9 & 1 & $0.053 *$ & 0.818 \\
No Tertiary & & & & & & \\
Education & $49(29.7)$ & $116(70.3)$ & 165 & & & \\
Tertiary & & & & & & \\
Years in Work & $14(23.0)$ & $47(77.0)$ & 61 & 3 & $11.229^{*}$ & 0.011 \\
$0-9$ & $25(42.4)$ & $34(57.6)$ & 59 & & & \\
$10-19$ & $12(32.6)$ & $26(67.4)$ & 38 & & & \\
$20-29$ & $1(6.3)$ & $15(93.7)$ & 16 & & & \\
$30+$ & & & & &
\end{tabular}

*Adjusted Chi square

\section{Discussion}

Less than half of respondents had good knowledge of GMFs. It is expected that trained agricultural workers have very good knowledge on GMFs by the virtue of their involvement in agriculture and efforts to embrace modern technology to meet the food needs of the growing population. It was lower than the self-reported good knowledge in almost three quarters of farmers in Poland ${ }^{11}$ but higher than the level of good knowledge reported by less than a quarter of doctors in Turkey. ${ }^{12}$ Among medical and dental students in a similar study in Lagos ${ }^{9}$ and among medical doctors in Jos, Nigeria, ${ }^{13}$ only one in every 6 and 1 in every 5 respondents respectively had good knowledge of GMFs. This is however expected as the medical students and doctors are likely to be less experienced and less exposed to information on genetically modified foods than the agricultural workers. The main source of information for respondents on GMFs was undergraduate curriculum. This was unlike what was reported in a similar study in Kenya where newspaper articles were identified as the main source of their information. ${ }^{14}$ In contrast also, Journals were identified as the main source of information on GMFs by scientists in South West Nigeria. ${ }^{15}$ The study showed that years of work experience had statistically significant association with both knowledge and perception of GMFs. It was as expected since experience generally imparts knowledge and good knowledge improves positive perception.

This study reported good perception of 
GMFs in only a third of respondents. This small proportion of respondents with good perception is buttressed by the fact that less than half of them had good knowledge of GMFs. Poor knowledge and perception are proxy indicators of the likely poor acceptability of GMFs among the agricultural workers. It may also portend likely rejection of GMFs by the general public since agricultural workers who are expected to be knowledgeable on these foods and who should project it to the public have poor perception of it. It may also imply non-acceptance of the technology by the agricultural workers. This finding is much better than that reported among respondents in the feed industry in China where positive perception was reported in less than a tenth of the respondents. ${ }^{16}$ It is worth noting that the China study was carried out when the technology was still relatively new and the perception still poor. Another study among agricultural scientists in south west Nigeria showed good perception of GMFs in $50 \%$ of the respondents. ${ }^{14}$ South western Nigeria generally has a higher literacy level and is much more exposed to modern technology than northern Nigeria where our study was carried out and this could explain the difference in perception in the two studies.

Findings from this study provide quantitative baseline data on the knowledge and perception of GMFs among agricultural workers in Jos. The implication of these findings is that a lot of GMF education still needs to be carried out on agricultural workers. A further qualitative study will provide more indepth analysis of the knowledge, concerns and other perspectives of agricultural workers in Jos on GMFs.

\section{Conclusion}

This study shows that the knowledge and perception of genetically modified foods are poor among agricultural workers in Jos metropolis. It is recommended that agricultural institutions improve the knowledge of their workers on genetically modified foods by regular and continuous training. Also, undergraduate curricula should have genetic engineering and related concepts incorporated into them. This will enhance the acceptance and utilization of these products by agricultural workers and the general public.

\section{References}

1. Panzarini NH, Bittencourt JVM, Matos EAS and Wosiack PA.

Biotechnology in agriculture: The perception of farmers on the inclusion of Genetically Modified Organisms ( GMOs ) in agricultural production. African Journal of Agricultural Research 2015;10(7):631-636.

2. Arun KR, Sathish KD, Gayatriv NT and Nishanth T. A Comprehensive Assessment and Perception of Genetically Modified Foods. J Genet Syndr Gene Ther. 2011;2:1-6.

3. Šrorgo A, Ambrožič-Dolinšek JU, Sak M, Özel M. Knowledge about and acceptance of genetically modified organisms among preservice teachers: A comparative study of Turkey and Slovenia. Electron J Biotechnol. 2011;14(4):5.

4. Raman R. The impact of Genetically Modified (GM) crops in modern agriculture: A review. GM Crops Food 2017; 8(4):195208

5. Lewis CP, Newell JN, Herron CM, Nawabu H.Tanzanian 
farmers' knowledge and attitudes to GM biotechnology and the potential use of GM crops to provide improved levels of food security. A Qualitative Study. BMC Public Health 2010;407 doi:10.1186/1471-2458-10-407

6. Wunderlich S, Gatto KA. Consumer Perception of Genetically Modified Organisms and Sources of Information. Adv Nutr An Int Rev J [Internet]. 2015;6(6):84251. Available from: http://advances.nutrition.org/cgi/do i/10.3945/an.115.008870

7. Autade RH, Jadhav RM, Gaikar PS, Jori DB, Antre SH, Reddy PG. Farmers perception, knowledge and attitude towards Biotech (GM) crops at Agrowon AgriExpo A survey. Int J Agric Environ Biotechnol [Internet]. 2015;8(3):753. Available from: http://www.indianjournals.com/ijor .aspx?target $=$ ijor:ijaeb $\&$ volume $=8$ \&issue $=3$ \&article $=029$

8. Pruitt MJ. Consumer Perceptions and Knowledge of Genetically Modified Organisms in Belgium: A Case Study of the Potato Event. 2014; Available at: http://scholarworks.uark.edu/aectu ht

9. Ebuehi OM, Ailohi OL.

Genetically Modified ( GM ) Foods / Organisms: Perspectives of Undergraduate Medical and Dental Students of the College of Medicine, University of Lagos, Lagos, Nigeria. Food and Public Health 2012; 2(6):281295.

10. Araoye MO. Subjects Selection. In:
Parakoyi B, editor. Research Methodology with statistics for Health and Social Sciences. 1st ed. Ilorin: Nathadex Publishers; 2004. P 118.

11. Rzymski P and Krolczyk A. Attitudes towards genetically modified organisms in Poland: to GMO or not to GMO? Food security 2016; 8(3):689-697

12. Savas H. Medical Doctors Perceptions of Genetically Modified Foods. J Clin Anal Med. 2014;7(112):172-175.

13. Daboer JC, Zaman M, Birdling NN, Maigamo NY, Orya EE, Idogho J. et al. Knowledge and perception of Genetically modified foods among medical doctors of Jos University Teaching Hospital Jos, Nigeria. Journal of Epidemiological Society of Nigeria 2018; 1(2):2936.

14. Kagai KK. Assessment of Public Perception, Awareness and Knowledge on Genetically Engineered Food Crops and their Products in Trans-Nzoia County, Kenya. J Dev Sustain Agric. 2011;6(2):164-180.

15. Alarima CI. Knowledge and perception of genetically modified foods among agricultural scientists in south-west Nigeria. Int J Sustain Dev. 2011;02(06):5663

16. Deng H, Hu R, Pray C, Jin Y. Perception and Attitude toward GM Technology among Agribusiness Managers in China as Producers and as Consumers. Sustainability 2019;15(5):1-17. 